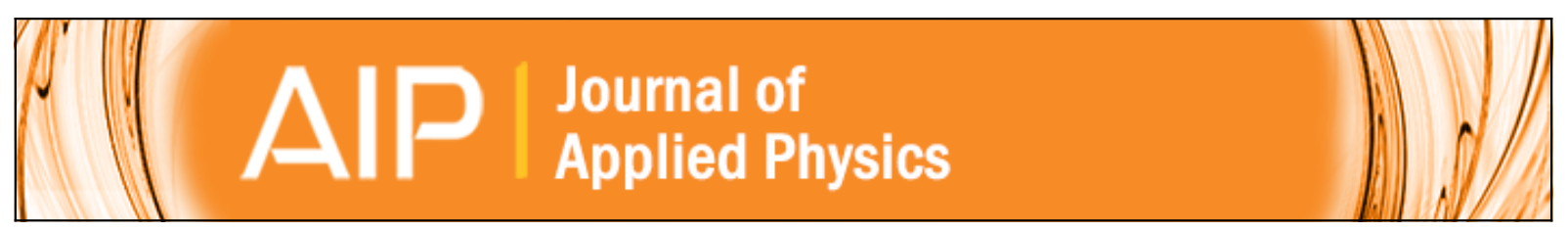

\title{
Laser-induced particle size tuning and structural transformations in germanium nanoparticles prepared by stain etching and colloidal synthesis route
}

Ali Karatutlu, William Little, Osman Ersoy, Yuanpeng Zhang, Isa Seker, and Andrei Sapelkin

Citation: Journal of Applied Physics 118, 244303 (2015); doi: 10.1063/1.4939066

View online: http://dx.doi.org/10.1063/1.4939066

View Table of Contents: http://scitation.aip.org/content/aip/journal/jap/118/24?ver=pdfcov

Published by the AIP Publishing

\section{Articles you may be interested in}

Ge nanoparticle formation by thermal treatment of $\mathrm{rf}$-sputtered $\mathrm{ZrO} 2 / \mathrm{ZrGe} 2 \mathrm{O} 3$ superlattices

J. Appl. Phys. 113, 044303 (2013); 10.1063/1.4780033

Microstructure-reactivity relationship of $\mathrm{Ti}+\mathrm{C}$ reactive nanomaterials

J. Appl. Phys. 113, 024302 (2013); 10.1063/1.4773475

Synthesis of zinc oxide nano-particles by mechano-thermal route

AIP Conf. Proc. 1476, 335 (2012); 10.1063/1.4751623

Perovskite phase transformation in $0.65 \mathrm{~Pb}(\mathrm{Mg} 1 / 3 \mathrm{Nb} 2 / 3) \mathrm{O} 3-0.35 \mathrm{PbTiO} 3$ nanoparticles derived by sol-gel

J. Appl. Phys. 111, 024314 (2012); 10.1063/1.3677974

Water soluble CdS nanoparticles with controllable size prepared via femtosecond laser ablation

J. Appl. Phys. 102, 064304 (2007); 10.1063/1.2781382

\section{AlP | Journal of Applied Physics \\ INTRODUCING INVITED PERSPECTIVES Ultrafast magnetism and THz spintronics Authors: Jakob Walowski and Markus Münzenberg}




\title{
Laser-induced particle size tuning and structural transformations in germanium nanoparticles prepared by stain etching and colloidal synthesis route
}

\author{
Ali Karatutlu, ${ }^{1,2, a)}$ William Little, ${ }^{1}$ Osman Ersoy, ${ }^{1}$ Yuanpeng Zhang, ${ }^{1}$ Isa Seker, ${ }^{3}$ \\ and Andrei Sapelkin ${ }^{1}$ \\ ${ }^{1}$ Centre for Condensed Matter and Materials Physics, School of Physics and Astronomy, Queen Mary, \\ University of London, London E1 4NS, United Kingdom \\ ${ }^{2}$ Electrical and Electronics Engineering, Bursa Orhangazi University, 16310 Ylldırım/Bursa, Turkey \\ ${ }^{3}$ Bio-Nanotechnology Research and Development Centre, Fatih University, 34500 Buyukcekmece, \\ Istanbul, Turkey
}

(Received 28 July 2015; accepted 30 November 2015; published online 29 December 2015)

\begin{abstract}
In this study, with the aid of Raman measurements, we have observed transformations in small ( $\sim 3 \mathrm{~nm}$ and $\sim 10 \mathrm{~nm}$ ) free-standing Ge nanoparticles under laser light exposure. The nanoparticles were obtained by the chemical stain etching of a monocrystalline Ge wafer and of Ge powder and by colloidal synthesis route. We found that the transformation path depends on laser power and exposure time. At relatively low values of the laser power $(2 \mathrm{~mW})$ over a period of $100 \mathrm{~min}$, the Raman signal indicates transformation of the sample from a nanocrystaline to bulk-like state, followed by partial oxidation and finally a conversion of the entire sample into alpha-quartz type $\mathrm{GeO}_{2}$. However, when the laser power is set at $60 \mathrm{~mW}$, we observed a heat release during an explosive crystallization of the nanocrystalline material into bulk Ge without noticeable signs of oxidation. Together with the transmission electron microscopy measurements, these results suggest that the chemical stain etching method for the preparation of porous Ge may not be a top-down process as has been widely considered, but a bottom up one. Systematic studies of the laser exposure on Ge nanoparticles prepared by colloidal synthesis results in the fact that the explosive crystallisation is common for $\mathrm{H}$-terminated and partially disordered $\mathrm{Ge}$ nanoparticles regardless of its particle size. We suggest possible bio-medical applications for the observed phenomena. (C) 2015 AIP Publishing LLC.
\end{abstract}

[http://dx.doi.org/10.1063/1.4939066]

\section{INTRODUCTION}

Germanium $(\mathrm{Ge})$ nanomaterials were recently demonstrated to have a great potential in applications including lithium ion batteries, ${ }^{1}$ photonics, ${ }^{2}$ and bio-imaging. ${ }^{3,4}$ Over the last 20 years, Ge nanoparticles were shown to be synthesized using several physical and chemical methods. ${ }^{5-17}$ Furthermore, the crystallization of amorphous Ge (a-Ge) and a low cost of forming epitaxy were also shown using various light sources such as excimer laser, ${ }^{18,19}$ pulsed-laser, ${ }^{20-22}$ flash lamp, ${ }^{23}$ and diode laser. ${ }^{24}$ Upon the exposure of amorphous samples to the light sources, a phenomenon called "explosive crystallization" can be accompanied by an energy release and can be observed under a microscope as formation of concentric shells on the amorphous surface of the film. ${ }^{24,25}$ This energy release is the latent heat of crystallisation caused by a transition from the amorphous state of the sample to its crystalline state. The effect is not only limited to Ge but also can be observed in other materials, ${ }^{25,26}$ and the explosive crystallization effect was observed in hydrogenated amorphous samples. ${ }^{27}$ However, the effect in the latter was believed to be due to the release of the hydrogen

\footnotetext{
a) Author to whom correspondence should be addressed. Electronic addresses: a.karatutlu@qmul.ac.uk and ali.karatutlu@bou.edu.tr. Telephone: +904448268-1166. Fax: +902242114406.
}

from the sample which might form bubbles and can explode in sufficient concentrations. ${ }^{28}$ At the same time, a variety of nanoparticles-mostly gold ${ }^{29-32}$ and graphenew ${ }^{33-36}$-were used in photothermal therapy (PTT) due to their high thermal conductivity. We previously showed that H-terminated Ge nanoparticles can exhibit good biocompatibility at a cellular level and can be used in bio-imaging applications. ${ }^{37}$ Surface functionalised $\mathrm{Ge}$ nanoparticles were also demonstrated to show an enhanced antioxidant behaviour which could be desirable to improve anticancer activity. ${ }^{38}$ In this study, we show that structure and morphology of Ge nanoparticles can be controlled by laser irradiation. This suggests that they have potential as an alternative material that can be used in PTT. We also speculate that $\mathrm{H}$-terminated Ge nanoparticles may be used in controlling cell population in vitro and potentially in-vivo. Furthermore, we suggest that chemical stain etching may in fact be a bottom-up rather than a top-down process, at least in the case of $\mathrm{Ge}$.

\section{EXPERIMENTAL METHODS}

The chemical stain etching of bulk c-Ge powder (99.999\% pure, Sigma-Aldrich) was performed using a solution of $\mathrm{HF}: \mathrm{H}_{3} \mathrm{PO}_{4}: \mathrm{H}_{2} \mathrm{O}_{2}(200: 200: 1)^{39}$ for the preparation of $\mathrm{Ge}$ nanoparticles (sample p-Ge1). Hydrofluoric acid, HF (48 wt. $\%$ in $\mathrm{H}_{2} \mathrm{O}$ ); phosphoric acid, $\mathrm{H}_{3} \mathrm{PO}_{4}\left(85\right.$ wt. $\%$ in $\mathrm{H}_{2} \mathrm{O}$ ); 
and hydrogen peroxide $\left(30 \mathrm{wt}\right.$. $\%$ in $\mathrm{H}_{2} \mathrm{O}$ ) were used aspurchased from Sigma-Aldrich. For a second sample (sample $\mathrm{p}-\mathrm{Ge} 2$ ), the surface of a commercially available (111) oriented n-type Ge wafer ( $2 \mathrm{in}$. in diameter and $0.51 \mathrm{~mm}$ thick) was processed in a solution of $\left.\mathrm{HF}: \mathrm{H}_{3} \mathrm{PO}_{4}: \mathrm{H}_{2} \mathrm{O}_{2}(34: 17: 1)\right)^{5,11}$ Both etching solutions were prepared inside a polytetrafluoroethylene (PTFE) cell and stirred for $3 \mathrm{~h}$ (with the aid of a magnetic stirrer) under indoor light illumination during sample preparation. All the chemicals were used in the solution as-purchased from Sigma-Aldrich. The sample prepared from powder (p-Ge1) was re-suspended in ethanol without any further processing. In the sample prepared on the surface of the wafer (p-Ge2), the porous layer was gently scraped with a sharp blade and re-suspended in ethanol.

A third sample of Ge nanoparticles was prepared using a benchtop colloidal synthesis route (named as CS1 henceforth and their preparation and structure shown in our previous studies $^{37,40}$ ) so as to test the slow and fast crystallisation on the same sample.

A He-Ne laser beam with a wavelength of $632.8 \mathrm{~nm}$ focussed by a $20 \times$ objective and power of $2 \mathrm{~mW}$ or $60 \mathrm{~mW}$ was used for the growth and phase transformation of pGe1 and pGe2 for various exposure time. The Raman data of CS1 were taken using a dispersive Raman spectrometer (Model: The Thermo Scientific DXR Raman Microscope) in which a laser beam of $532 \mathrm{~nm}$ wavelength was focussed by a $20 \times$ objective and a $50 \times$ objective. A higher laser power range $(100 \mathrm{~mW}-800 \mathrm{~mW})$ at a wavelength of $1064 \mathrm{~nm}$ and coupled with FT Raman spectrometer (Model: The Thermo Scientific Nicolet NXR 9650 FT-Raman spectrometer) was utilised to test explosive crystallisation of CS1 sample. FT Raman data are usually taken in the near infrared region to detect unsymmetrical molecular bonds. Therefore, Ge-Ge symmetric stretching bond was not observed and FT Raman spectrometer system is only used to record the live video in order to determine at which laser power the explosive crystallisation phenomenon would occur.

The phonon confinement model based on RichterFauchet-Campbell model (RFC) $)^{41,42}$ was used to obtain the average particle size from the Raman signal. For that purpose, a code has been written in Matlab describing Raman intensity, $I$ as shown below (see in Equation (1)) using the following dispersion relation, ${ }^{43} \omega_{q}=\omega_{0}-104\left(\frac{q a}{2 \pi}\right)^{2}$ :

$$
I(\omega)=\int_{0}^{\frac{2 \pi}{a_{0}}} \frac{e^{-\left(\frac{q d_{0}}{4 \pi}\right)^{2}} a_{0} \pi q^{2}}{\left(\omega-\omega_{q}\right)^{2}+\left(\frac{\Gamma_{0}}{2}\right)^{2}} d q,
$$

where $a_{0}$ is the lattice parameter, $q$ is the phonon wave vector, $d_{0}$ is the particle size, $\omega_{q}$ is the phonon dispersion curve, and $\Gamma_{0}$ is the natural linewidth of the Raman peak. $\Gamma_{0}$ $=7 \mathrm{~cm}^{-1}$ is obtained from a calibration standard Ge powder, 99.999\% pure, Sigma-Aldrich).

Raman measurements were carried out using a Renishaw 1000 Raman microscope equipped with a $632.8 \mathrm{~nm} \mathrm{He}-\mathrm{Ne}$ laser (The laser spot size was $5 \mathrm{~mm}$ ). The experimental spectral resolution was $0.5 \mathrm{~cm}^{-1}$. The power was kept at $2 \mathrm{~mW}$ during the Raman spectra acquisition with the typical spectrum collection time was around 1 min. The substrates used in Raman measurements were glass slides for pGe1 and CS1 and a c-Si wafer for pGe2.

For TEM measurements, Ge nanoparticles are suspended in ethanol and then transferred on a commercial Carbon coated $\mathrm{Cu}$ grid by submerging the grid into the nanoparticles containing a microtube. TEM measurements were conducted at $200 \mathrm{keV}$.

\section{RESULTS AND DISCUSSION}

The first sample (p-Ge1) was prepared from bulk Ge powder. The resulting $\mathrm{p}-\mathrm{Ge} 1$ nanoparticles were yellow in color, as shown in Figure 1(c). TEM measurements were carried out to confirm the size of the as-prepared sample, and the average typical particle size was found to be $10 \pm 3 \mathrm{~nm}$ (Figure S1). Extended Raman data show the presence of a Ge-H stretching mode at $2048 \mathrm{~cm}^{-1}$ (Refs. 44 and 45) (see inset in Figure 1(a)). No signal corresponding to Ge-O modes (at $442 \mathrm{~cm}^{-1}$ ) was detected. The Raman mode corresponding to the Ge-Ge TO phonon mode was detected at $292 \mathrm{~cm}^{-1}$ (see Figure 1(a)). The mode is shifted towards lower frequencies with respect to that of crystalline bulk Ge at $300 \mathrm{~cm}^{-1}$ (see Figure 1(a)), has an asymmetric shape, and is broader than that observed in bulk Ge. Broadening and asymmetric peak shape as well as down-shift of the peak are expected for $\mathrm{Ge}$ nanoparticles ${ }^{7}$ and is due to phonon confinement effects. The RFC model ${ }^{41,42}$ was applied to estimate the size of Ge nanoparticles. Free-standing p-Ge1 nanoparticles were found to be $7.2 \mathrm{~nm}$ in size for an as-prepared sample (Figure S2). The average particle size difference observed between TEM and Raman data can be attributed to the influence of surface-related structural disorder. ${ }^{37,40}$

Following sample characterisation, we investigated the behavior of as-prepared nanoparticles upon $\mathrm{He}-\mathrm{Ne}$ laser exposure. Laser power was increased to $2 \mathrm{~mW}$, and the Raman spectra from $1 \mathrm{~min}$ of exposure to $100 \mathrm{~min}$ of the exposure were recorded (see Figure 1(b)). The most obvious observation is the shift of the Raman peak back to around $300 \mathrm{~cm}^{-1}$ (as found in bulk Ge).

Using the RFC model, the size of Ge nanoparticles was obtained and it was found to increase from $7.2 \mathrm{~nm}$ to $23.8 \mathrm{~nm}$ at the end of $35 \mathrm{~min}$ and then to the bulk at the end of $40 \mathrm{~min}$ (Figure 1(d) and Table S1). Thus, we conclude that the sample was transformed to bulk Ge at the end of 40 min as indicated by the value of the FWHM of the Raman peak $\left(\sim 7 \mathrm{~cm}^{-1}\right.$, close to that observed in bulk Ge reference). Further laser exposure in ambient environment yields oxidized Ge nanoparticles and ultimately results in full sample oxidation after $100 \mathrm{~min}$ as indicated by the appearance and growth of the Raman mode (at around $442 \mathrm{~cm}^{-1}$ ) corresponding to alpha-quartz type $\mathrm{GeO}_{2}$ (see Figures 1(b), S3, and S4, respectively, for the corresponding Raman spectra and the schematic of the growth and phase transformation of free-standing Ge nanoparticles upon exposure of $\mathrm{He}-\mathrm{Ne}$ laser in the supplementary material). Furthermore, by the end of the exposure period, the Raman signal corresponding to pure $\mathrm{Ge}\left(\right.$ at $300 \mathrm{~cm}^{-1}$ ) has completely disappeared (see Figure 1(b)). 

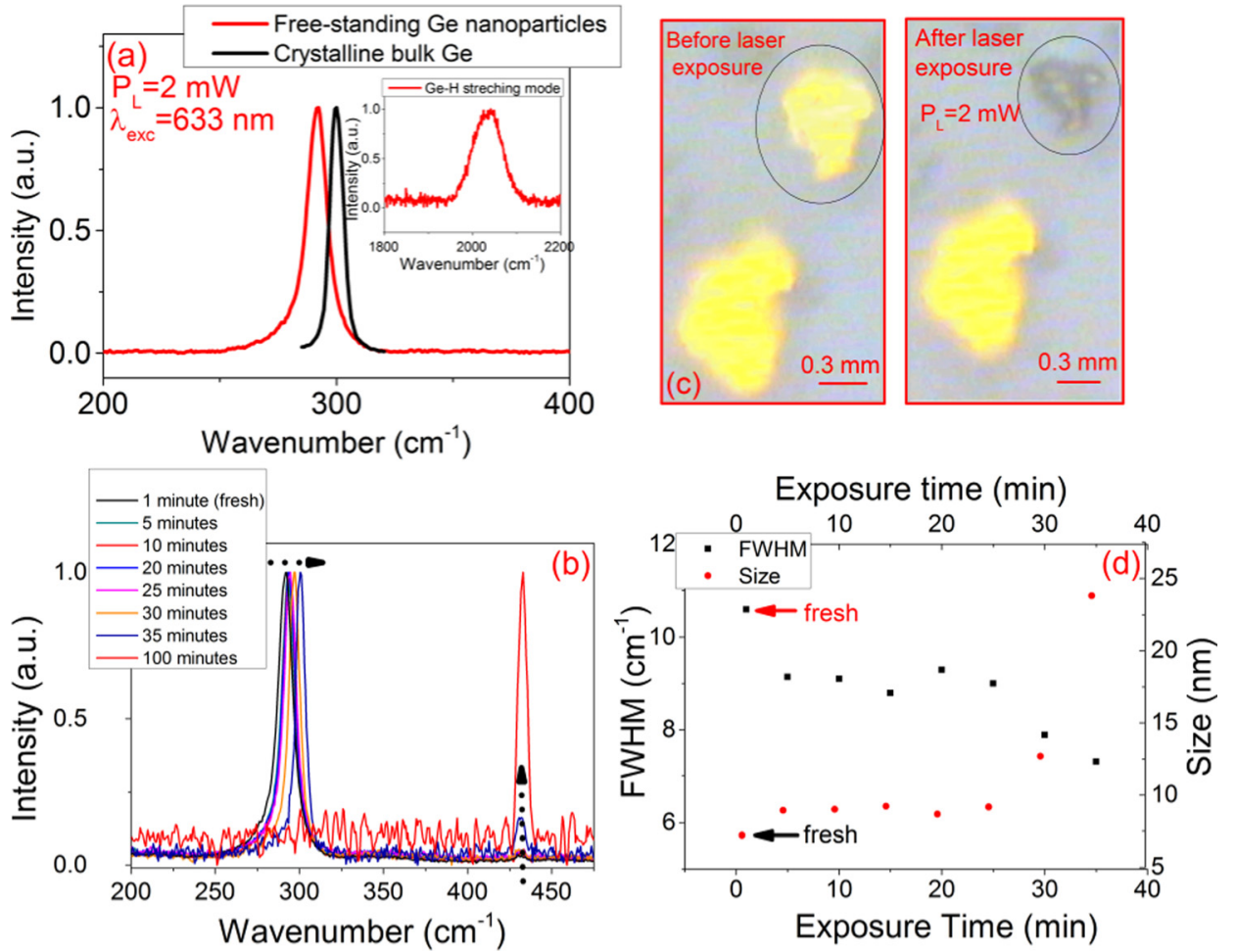

FIG. 1. (a) Raman shift of freestanding Ge nanoparticles before (asprepared) and that of crystalline bulk Ge. The inset shows Ge-H stretching mode at $2042 \mathrm{~cm}^{-1}$, which is an indication for H-termination of $\mathrm{Ge}$ nanoparticles. (b) Raman spectra of $\mathrm{Ge}$ nanoparticles exposed to a He-Ne laser light with an excitation wavelength of $633 \mathrm{~nm}$ (laser power $=2 \mathrm{~mW}$ ) from 5 min to $100 \mathrm{~min}$. By the time of the laser exposure, Ge nanoparticles were grown in size. At the end of $35 \mathrm{~min}$, Ge nanoparticles begins transformation to $\alpha$-type $\mathrm{GeO}_{2}$, which was shown with $\mathrm{Ge}-\mathrm{O}$ stretching mode at $433 \mathrm{~cm}^{-1}$ (c) The picture of clusters of Ge nanoparticles before (fresh) and after the laser exposure $(\mathrm{t}=10 \mathrm{~min})$.(d) Size (red symbols) and FWHM (black symbols) change of Raman shift of Ge nanoparticles by the time of the He-Ne laser exposure were shown from $1 \mathrm{~min}$ (fresh sample) to $35 \mathrm{~min}$. As-prepared Ge nanoparticles were grown from $7.2 \mathrm{~nm}$ in size to $23.8 \mathrm{~nm}$ in size at the end of $35 \mathrm{~min}$.
The second set of Ge nanoparticles (p-Ge2) was prepared using the same chemical stain etching method on the surface of a Ge wafer. As shown in Figure 2(b), as-prepared p-Ge2 was also yellow in color. The Raman spectrum of asprepared p-Ge2 is given in Figure 2(a). The size of p-Ge was found to be $3.1 \mathrm{~nm}$ (see Figure 2(a)) using the RFC model. The origins of the particle size differences between $\mathrm{p}-\mathrm{Ge} 1$ and p-Ge2 samples are unclear at present, but may be related to the geometry of the precursors' surface (curved for powder vs planar for wafer) and kinetics of particle formation. Once a Raman spectrum of as-prepared p-Ge2 has been recorded, the laser power was changed to $60 \mathrm{~mW}$ and the visual appearance of the sample was observed to change instantly (Figure 2(c)). The Raman spectrum of p-Ge2 after the laser exposure is shown in Figure 2(a). The data show that the Ge nanoparticles were transformed into a bulk-like phase and annealed upon exposure of the laser light. In Figure 2(c), one can see that the samples are black in color after the laser exposure. A concentric burn-like pattern observed on the $\mathrm{Si}$ substrate suggests that the process is accompanied by significant heat release sufficient to cause $\mathrm{Si}$ substrate annealing.

Thus, our results for $\mathrm{p}-\mathrm{Ge} 1$ and $\mathrm{p}-\mathrm{Ge} 2$ samples suggest that exposure to the laser light results in nanoparticle size increase and a change in morphology and structure. Furthermore, the exposure to $60 \mathrm{~mW}$ laser power indicates a significant heat release during crystallisation. The latter clearly suggests a transformation from a metastable (or partially metastable) phase. At this point, the energy is considered to be released due to the transition from the disordered state of Ge nanoparticles to its crystalline state triggered by the laser exposure (Figure S5). Considering the position and width of the Raman peak and the size discrepancy observed between the Raman and TEM measurements, we suggest that this metastable phase is most likely to be disordered diamond-type structure. The presence of disordered Ge was also previously shown in our study using EXAFS techniques. $^{37,40}$ The fact that stain etching of $\mathrm{c}-\mathrm{Ge}$ yields a

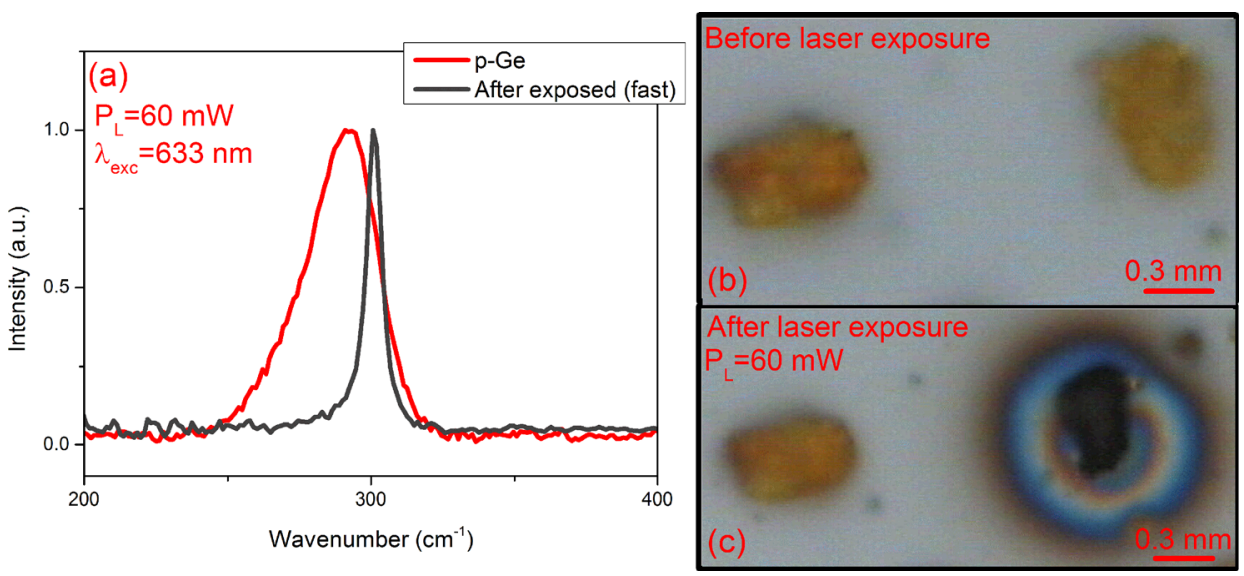

FIG. 2. (a) Raman shift of p-Ge before (as-prepared) and after the prompt laser exposure. (b) The picture of clusters of p-Ge before (fresh) and (c) after the prompt laser exposure. When the laser power is $60 \mathrm{~mW}$, the transformation from the disordered to the crystalline form is prompt which can be observed via the release of the energy from the sample to the environment and was optically recorded as a concentric shell on the substrate. 
metastable (amorphous) phase suggests that the process of preparation may not in fact be a top-down as has been previously thought, but a bottom-up one.

When we revisit some of the pioneering chemical stain etching studies of $\mathrm{Si}^{46-49}$ in fluoride solutions since 1990 s, various chemical solutions but the very same principle were applied. A fluorine containing etchant (e.g., $\mathrm{HF}$ or $\mathrm{HBF}_{4}$ or $\mathrm{HSbF}_{6}$ ), an oxidant $\left(\mathrm{HNO}_{3}\right.$ or $\mathrm{H}_{2} \mathrm{O}_{2}$ or $\left.\mathrm{H}_{2} \mathrm{O}\right)$, and sometimes a surfactant with/without a catalyst (a UV-light illumination and a metal ion assistance) were applied to initiate the etching process so as to remove atoms/clusters from a $\mathrm{Si}$ wafer which would end with a H-termination on the wafer surface. Recently, Kolasinski reported the modified stain etching mechanism of $\mathrm{Si}^{50}$ (also known as Gerischer mechanism ${ }^{51}$ ). The mechanism is rather complex and considered to be occurring in several steps. In the first and the second steps of the etching mechanism, the etching requires a hole $\left(\mathrm{h}^{+}\right)$formation and transfer of this hole to the surface. In the chemical context, in the first step, the surface is H-terminated which would be later desorbed and then replaced by $\mathrm{F}^{-}$ions in the forthcoming steps. At the end, following these steps will lead to the decomposition of a $\mathrm{Si}$ wafer (removal of $\mathrm{Si}$ atoms/clusters) and the formation of a porous structure with H-termination on the surface. The same approach was later on applied to germanium using chemical stain etching. ${ }^{11,52}$ Thus, the stain etching mechanism was also interpreted within a similar model-removal of material to form porous structure (see Figure 3). However, it is difficult to explain the formation of a metastable amorphous structure by the mechanism described above. Thus, we suggest that the formation of $\mathrm{p}$-Ge using chemical stain etching may in fact proceed by the removal of atoms/clusters from the bulk precursor followed by the nucleation back onto substrate (when Ge wafer is used) or nucleation and growth in the solution (when powder is used) into partially amorphous nanoparticles (see Figure 3).

We believe that besides shedding fresh light onto the well-known method of nanoparticle preparation, the observed laser effects can find bio-medical and oxygenharvesting applications. We found two different scenarios of behaviour of Ge nanoparticles when exposed to the laser light of $2 \mathrm{~mW}$ and $60 \mathrm{~mW}$ at $632.8 \mathrm{~nm}$. The first scenario is the slow growth and oxidation of the Ge nanoparticles upon the $2 \mathrm{~mW}$ laser exposure. Under these conditions, Ge nanoparticles can be considered as an anti-oxidant for controlled up-take of the reactive oxygen species (ROS) in cells. This should provide a valuable tool to study the influence of ROS on cancer development ${ }^{54}$ and perhaps even as a cancer prevention therapy. Furthermore, ROS-mediated strategy was also shown to help reduce drug resistance. ${ }^{55}$ Interestingly, Ge food supplements are already on the market and their positive effects on the immune system were studied by some researchers. ${ }^{56,57}$ Recently, quercetin surface-functionalized Ge nanoparticles were shown to enhance the anti-oxidant and anti-cancer activities. ${ }^{38}$ Therefore, one can consider Ge nanoparticles as a regulator of the ROS capacity and thus to have significant therapeutic implications.

The second scenario under laser exposure is explosive crystallization with a substantial heat release. Photosensitive smart polymer coated gold nanocages ${ }^{58}$ were successfully demonstrated previously to be used as a drug carrying and release system upon near infrared laser excitation. A variety of nanoparticles-mostly gold ${ }^{29-32}$ and graphene ${ }^{33-36}$ - were used in PTT due to their high thermal conductivity. Here, we speculate that the prompt energy release from free-standing Ge nanoparticles upon He-Ne laser excitation (see Figure 1(d)) may be used to control cell population and proliferation using relatively low laser power. We believe that the energy release from free-standing Ge nanoparticles can be controlled and used in PPT. Particle growth requires proximity of other particles as otherwise there is no material to grow. This suggests that if a cell can take sufficient material then the explosive crystallisation scenario can be used to kill a cell, for example. Our previous studies ${ }^{37}$ indicate that cells can uptake certain amount of Ge nanoparticles sufficient for imaging applications. However, more work is required to establish specific amounts sufficient for PPT type therapy both in-vitro and in-vivo.

Furthermore, colloidally prepared and partially disordered Ge nanoparticles (named as CS1 henceforth and their preparation and structure shown in our previous studies ${ }^{37,40}$ ) were exposed to various laser powers including $0.5 \mathrm{~mW}$,

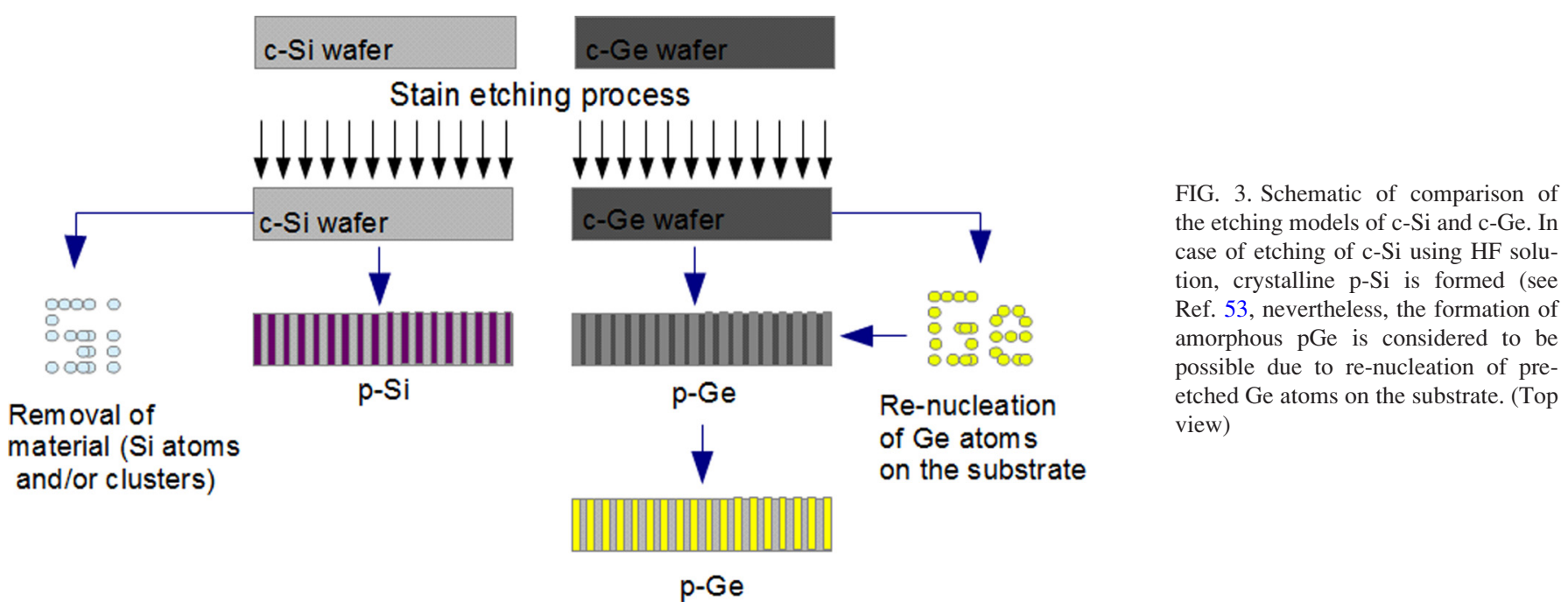




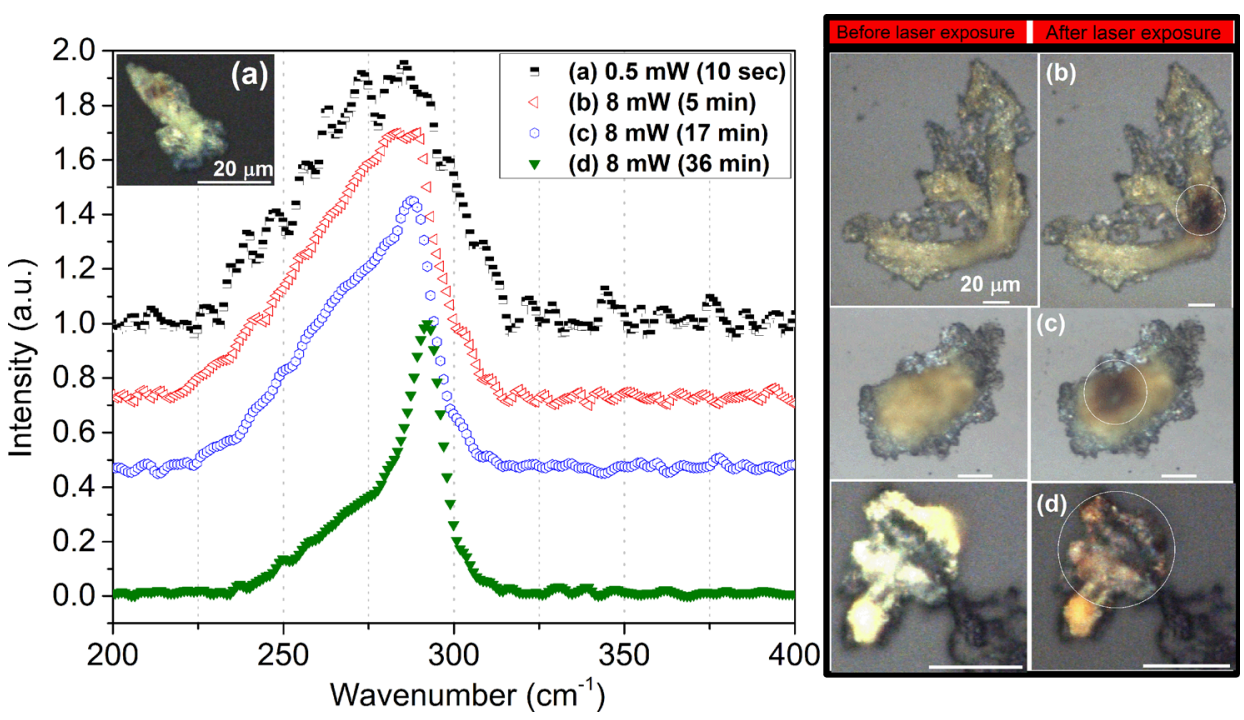

FIG. 4. Raman spectra and visual appearances of (a) as-prepared and the laser exposed $\mathrm{Ge}$ nanoparticles at 8 $\mathrm{mW}$ for (b) $5 \mathrm{~min}$, (c) $17 \mathrm{~min}$, and (d) $36 \mathrm{~min}$. Scale bars are $20 \mu \mathrm{m}$. The laser beam was focussed by a $50 \times$ and a $20 \times$ objectives.
$8 \mathrm{~mW}$, and $100-800 \mathrm{~mW}$ in order to combine these two scenarios (slow and fast crystallisation) and to perform a systematic study of the laser exposure on the same sample. Raman spectra of CS1 are shown in Figure 4 when the laser power was set to $0.5 \mathrm{~mW}$ and $8 \mathrm{~mW}$. Size analyses of CS1 using RFC model after the laser exposure for $10 \mathrm{~s}$ at $0.5 \mathrm{~mW}$ and for $5 \mathrm{~min}, 17 \mathrm{~min}$, and $36 \mathrm{~min}$ at $8 \mathrm{~mW}$ were done and found to be $2.4 \mathrm{~nm}\left(\mathrm{FWHM}=48.4 \mathrm{~cm}^{-1}\right), 2.5 \mathrm{~nm}$ (FWHM $\left.=43.2 \mathrm{~cm}^{-1}\right), 2.7 \mathrm{~nm} \quad\left(\mathrm{FWHM}=38.1 \mathrm{~cm}^{-1}\right)$, and $5.1 \mathrm{~nm}$ $\left(\mathrm{FWHM}=15 \mathrm{~cm}^{-1}\right)$, respectively. The characteristics of the size increase of CS1 upon the laser exposure were observed to be consistent with the laser exposed samples prepared by the etching method (see Figure 1(d)).

Images of CS1 samples taken before and after the laser exposure for $5 \mathrm{~min}, 17 \mathrm{~min}$, and $36 \mathrm{~min}$ at $8 \mathrm{~mW}$ are shown in Figures 4(b), 4(c), and 4(d), respectively. Later, a higher laser power range $(100 \mathrm{~mW}-800 \mathrm{~mW})$ at a wavelength of $1064 \mathrm{~nm}$ was utilised to understand how in the second scenario, explosive crystallisation would take place in CS1 sample. Images of the changes upon the laser exposure with laser power from $100 \mathrm{~mW}$ to $700 \mathrm{~mW}$ were recorded and are given in Figures 5(a)-5(e). The images from Figures 5(a)-5(c) show that two Ge clusters are exploded when $700 \mathrm{~mW}$ laser power was reached. Figure 5(d) shows an image of the case just before the moment of the explosion was recorded and shown in Figure 5(e). The real time video of the explosive crystallisation of CS1 was also recorded (see video (a) of Ref. 59). In addition, an energy release forms a halo around the Ge cluster when $500 \mathrm{~mW}$ of the laser power was set and this process was observed to be reversible and energy release could be controlled by the laser power (see video (b) of Ref. 59). The images as well as the Raman data indicate that the laser exposure at relatively smaller laser power can change the visual appearance and the structure of the Ge nanoparticles. This trend seems to be common in all $\mathrm{H}$-terminated and (partially) disordered Ge nanoparticles (see Figures 1(b), 1(c), 2(a), and 2(c)).

\section{CONCLUSION}

We found that Ge nanoparticles prepared by chemical stain etching can undergo transformation to bulk-like crystalline phase. The transformation path depends on laser power and laser exposure time. At relatively low values of the laser power $(2 \mathrm{~mW})$ over the period of $100 \mathrm{~min}$, the Raman signal indicates the transformation of the sample from a nanocrystalline to a bulk-like state, followed by partial oxidation and finally a conversion of the entire sample into alpha-quartz type $\mathrm{GeO}_{2}$. At a higher laser power $(60 \mathrm{~mW})$, we observed heat release during an explosive crystallization of the nanocrystalline material into bulk-like Ge without noticeable

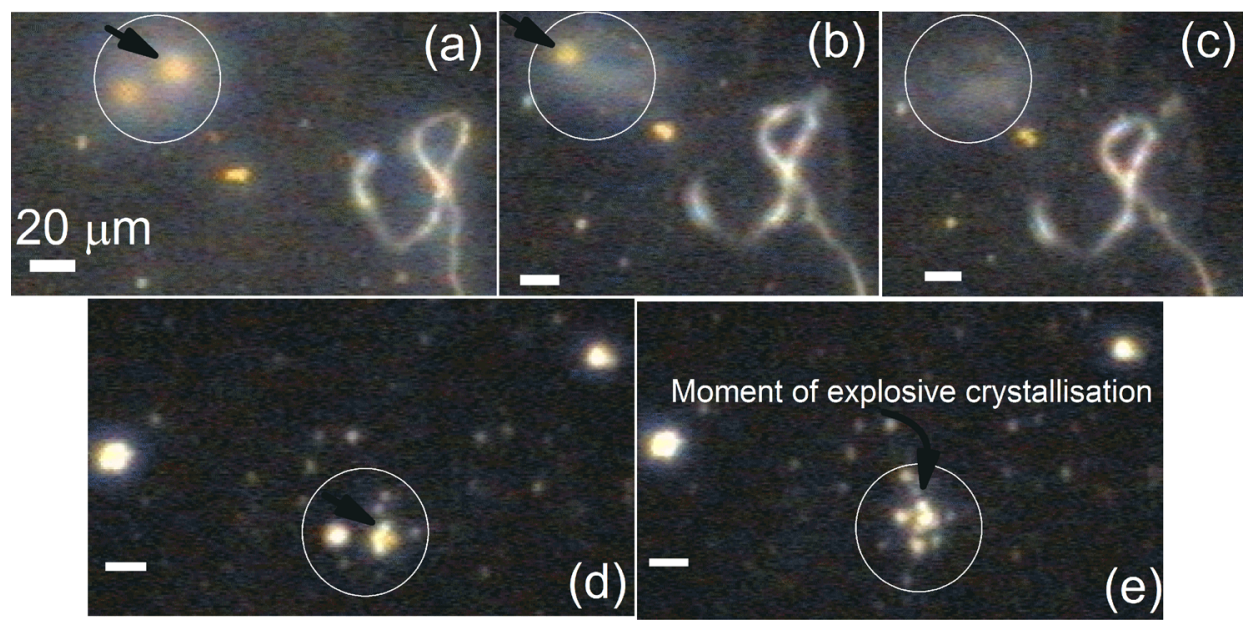

FIG. 5. Visual appearances of CS1 (a) before the explosive crystallisation, the laser beam exposed to the Ge cluster pointed by an arrow whose power was changed from $100 \mathrm{~mW}$ to $600 \mathrm{~mW}$ and then (b) $700 \mathrm{~mW}$ was reached and the explosive crystallisation suddenly took place. In (c), the disappearance of the second Ge cluster pointed by an arrow in (b) is presented. In (d), a Ge cluster was exposed to $100 \mathrm{~mW}-800 \mathrm{~mW}$ and in (e), the shatter of the Ge cluster was shown in the moment of the explosive crystallisation. 
signs of oxidation. Together with the transmission electron microscopy measurements, these results suggest that the stain etching method for the preparation of porous Ge may not be a top-down but a bottom-up process. Systematic studies of the laser exposure on Ge nanoparticles prepared by colloidal synthesis shows that explosive crystallisation is shared by $\mathrm{H}$-terminated and (partially) disordered Ge nanoparticles, no matter what the nanoparticle size is. We suggest that the laser effects observed in this work can be used for phototherapy and oxygen harvesting applications.

\section{ACKNOWLEDGMENTS}

William R. Little was grateful to The South East Physics Network (SEPnet). Osman Ersoy acknowledges the Turkish Ministry of National Education. This work has been supported in part by UK BBSRC Grant No. BB/J001473/1.

${ }^{1}$ Y. J. Cho, H. S. Im, H. S. Kim, Y. Myung, S. H. Back, Y. R. Lim, C. S. Jung, D. M. Jang, J. Park, E. H. Cha, W. Il Cho, F. Shojaei, and H. S. Kang, ACS Nano 7, 9075 (2013).

${ }^{2}$ E. J. Henderson, M. Seino, D. P. Puzzo, and G. A. Ozin, ACS Nano 4, 7683 (2010).

${ }^{3}$ T. N. Lambert, N. L. Andrews, H. Gerung, T. J. Boyle, J. M. Oliver, B. S. Wilson, and S. M. Han, Small 3, 691 (2007).

${ }^{4}$ S. Prabakar, A. Shiohara, S. Hanada, K. Fujioka, K. Yamamoto, and R. D. Tilley, Chem. Mater. 22, 482 (2010).

${ }^{5}$ G. Kartopu, S. C. Bayliss, V. a. Karavanskii, R. J. Curry, R. Turan, and A. V. Sapelkin, J. Lumin. 101, 275 (2003)

${ }^{6}$ Y. Maeda, N. Tsukamoto, Y. Yazawa, Y. Kanemitsu, and Y. Masumoto, Appl. Phys. Lett. 59, 3168 (1991).

${ }^{7}$ J. R. Heath, J. J. Shiang, and A. P. Alivisatos, J. Chem. Phys. 101, 1607 (1994).

${ }^{8}$ B. R. Taylor, S. M. Kauzlarich, G. R. Delgado, and H. W. H. Lee, Chem. Mater. 11, 2493 (1999).

${ }^{9}$ H. Yang, X. Wang, H. Shi, F. Wang, X. Gu, and X. Yao, J. Cryst. Growth 236, 371 (2002).

${ }^{10}$ B. R. Taylor, G. A. Fox, L. J. Hope-Weeks, R. S. Maxwell, S. M. Kauzlarich, and H. W. Lee, Mater. Sci. Eng. B 96, 90 (2002).

${ }^{11}$ V. Karavanskii, A. Lomov, A. Sutyrin, V. Bushuev, N. Loikho, N. Melnik, T. Zavaritskaya, and S. Bayliss, Thin Solid Films 437, 290 (2003).

${ }^{12}$ N. Myung, X. Lu, K. P. Johnston, and A. J. Bard, Nano Lett. 4, 183 (2004).

${ }^{13}$ X. Lu, B. A. Korgel, and K. P. Johnston, Nanotechnology 16, S389 (2005).

${ }^{14}$ E. J. Henderson, C. M. Hessel, and J. G. C. Veinot, J. Am. Chem. Soc. 130, 3624 (2008).

${ }^{15}$ N. H. Chou, K. D. Oyler, N. E. Motl, and R. E. Schaak, Chem. Mater. 21, 4105 (2009).

${ }^{16}$ D. D. Vaughn, J. F. Bondi, and R. E. Schaak, Chem. Mater. 22, 6103 (2010).

${ }^{17}$ D. A. Ruddy, J. C. Johnson, E. R. Smith, and N. R. Neale, ACS Nano 4, 7459 (2010).

${ }^{18}$ T. Sameshima, H. Watakabe, H. Kanno, T. Sadoh, and M. Miyao, Thin Solid Films 487, 67 (2005).

${ }^{19}$ C. Y. Ong, K. L. Pey, K. K. Ong, D. X. M. Tan, X. C. Wang, H. Y. Zheng, C. M. Ng, and L. Chan, Appl. Phys. Lett. 94, 082104 (2009).

${ }^{20}$ M. Mulato, D. Toet, G. Aichmayr, P. V. Santos, and I. Chambouleyron, Appl. Phys. Lett. 70, 3570 (1997).

${ }^{21}$ M. Mulato, D. Toet, G. Aichmayr, A. Spangenberg, P. V. Santos, and I. Chambouleyron, J. Non. Cryst. Solids 227-230, 930 (1998).

${ }^{22}$ O. Salihoglu, U. Kuüruüm, H. Gul Yaglioglu, A. Elmali, and A. Aydinli, J. Appl. Phys. 109, 123108 (2011).

${ }^{23}$ K. Ohdaira and H. Matsumura, Thin Solid Films 524, 161 (2012).

${ }^{24}$ K. Sakaike, S. Higashi, H. Murakami, and S. Miyazaki, Thin Solid Films 516, 3595 (2008).

${ }^{25}$ H.-D. Geiler, E. Glaser, G. Goütz, and M. Wagner, J. Appl. Phys. 59, 3091 (1986).
${ }^{26}$ K. Ohdaira, T. Nishikawa, and H. Matsumura, J. Cryst. Growth 312, 2834 (2010).

${ }^{27}$ D. Toet, P. M. Smith, T. W. Sigmon, T. Takehara, C. C. Tsai, W. R. Harshbarger, and M. O. Thompson, J. Appl. Phys. 85, 7914 (1999).

${ }^{28}$ Y. Miyata, M. Furuta, T. Yoshioka, and T. Kawamura, J. Appl. Phys. 73, 3271 (1993).

${ }^{29}$ C. Loo, A. Lowery, N. Halas, J. West, and R. Drezek, Nano Lett. 5, 709 (2005).

${ }^{30}$ X. Huang, I. H. El-Sayed, W. Qian, and M. A. El-Sayed, J. Am. Chem. Soc. 128, 2115 (2006).

${ }^{31}$ M. P. Melancon, W. Lu, Z. Yang, R. Zhang, Z. Cheng, A. M. Elliot, J. Stafford, T. Olson, J. Z. Zhang, and C. Li, Mol. Cancer Ther. 7, 1730 (2008).

${ }^{32}$ J. Z. Zhang, J. Phys. Chem. Lett. 1, 686 (2010).

${ }^{33}$ W. Lu, C. Xiong, G. Zhang, Q. Huang, R. Zhang, J. Z. Zhang, and C. Li, Clin. Cancer Res. 15, 876 (2009).

${ }^{34}$ K. Yang, S. Zhang, G. Zhang, X. Sun, S.-T. Lee, and Z. Liu, Nano Lett. 10, 3318 (2010).

${ }^{35}$ J. T. Robinson, S. M. Tabakman, Y. Liang, H. Wang, H. S. Casalongue, D. Vinh, and H. Dai, J. Am. Chem. Soc. 133, 6825 (2011).

${ }^{36}$ K. Yang, J. Wan, S. Zhang, B. Tian, Y. Zhang, and Z. Liu, Biomaterials 33, 2206 (2012).

${ }^{37}$ A. Karatutlu, M. Song, A. P. Wheeler, O. Ersoy, W. R. Little, Y. Zhang, P. Puech, F. S. Boi, Z. Luklinska, and A. V. Sapelkin, RSC Adv. 5, 20566 (2015).

${ }^{38}$ Y.-J. Guo, F. Yang, L. Zhang, J. Pi, J.-Y. Cai, and P.-H. Yang, Chem. Asian J. 9, 2272 (2014).

${ }^{39}$ The volumes of $15 \mathrm{ml}: 15 \mathrm{ml}: 0.075 \mathrm{ml}$ were used in the experiment for $\mathrm{HF}: \mathrm{H}_{3} \mathrm{PO}_{4}: \mathrm{H}_{2} \mathrm{O}_{2}$, respectively. The optimum conditions were found out at the end of 115 trials of various amounts of the chemicals. The amount of $\mathrm{H}_{2} \mathrm{O}_{2}$ in the solution is particularly important since exceeding $0.075 \mathrm{ml}$ of $\mathrm{H}_{2} \mathrm{O}_{2}$ may quickly cause the dissolution of all sample.

${ }^{40}$ Y. Zhang, A. Karatutlu, O. Ersoy, W. Little, G. Cibin, A. Dent, and A. Sapelkin, J. Synchrotron Radiat. 22, 105 (2015).

${ }^{41}$ I. H. Campbell and P. M. Fauchet, Solid State Commun. 58, 739 (1986).

${ }^{42}$ H. Richter, Z. P. Wang, and L. Ley, Solid State Commun. 39, 625 (1981).

${ }^{43}$ A. K. Das, S. Ghose, B. Dev, G. Kuri, and T. Yang, Appl. Surf. Sci. 165, $260(2000)$.

${ }^{44}$ H. C. Choi and J. M. Buriak, Chem. Commun. 2000, 1669.

${ }^{45}$ J. M. Buriak, Chem. Rev. 102, 1271 (2002).

${ }^{46}$ J. Sarathy, S. Shih, K. Jung, C. Tsai, K.-H. Li, D.-L. Kwong, J. C. Campbell, S.-L. Yau, and A. J. Bard, Appl. Phys. Lett. 60, 1532 (1992).

${ }^{47}$ A. J. Steckl, J. Xu, and H. C. Mogul, Appl. Phys. Lett. 62, 2111 (1993).

${ }^{48}$ X. Li and P. W. Bohn, Appl. Phys. Lett. 77, 2572 (2000).

${ }^{49}$ A. Parbukov, V. Beklemyshev, V. Gontar, I. Makhonin, S. Gavrilov, and S. Bayliss, Mater. Sci. Eng. C 15, 121 (2001).

${ }^{50}$ K. W. Kolasinski, Surf. Sci. 603, 1904 (2009).

${ }^{51} \mathrm{H}$. Gerischer and W. Mindt, Electrochim. Acta 13, 1329 (1968).

${ }^{52}$ M. Sendova-Vassileva, N. Tzenov, D. Dimova-Malinovska, M. Rosenbauer, M. Stutzmann, and K. V. Josepovits, Thin Solid Films 255, 282 (1995).

${ }^{53}$ A. G. Cullis and L. T. Canham, Nature 353, 335 (1991).

${ }^{54}$ O. Warburg, Science 123, 309 (1956).

${ }^{55}$ D. Trachootham, J. Alexandre, and P. Huang, Nat. Rev. Drug Discov. 8, 579 (2009).

${ }^{56}$ S. A. Levine and P. M. Kidd, J. Orthomol. Med. 1, 145 (1986).

${ }^{57}$ S. Goodman, Med. Hypotheses 26, 207 (1988).

${ }^{58}$ M. S. Yavuz, Y. Cheng, J. Chen, C. M. Cobley, Q. Zhang, M. Rycenga, J. Xie, C. Kim, K. H. Song, A. G. Schwartz, L. V. Wang, and Y. Xia, Nat. Mater. 8, 935 (2009).

${ }^{59}$ See supplementary material http://dx.doi.org/10.1063/1.4939066 for a TEM measurement of free-standing Ge nanoparticles, table of the values of the size of Ge nanoparticles found by the RFC model upon the exposure of a He-Ne laser light (laser power $=2 \mathrm{~mW}$ ), comparison of Raman shift from a reference bulk Ge powder and that from 40 min exposed Ge nanoparticles by the laser light (laser power $=2 \mathrm{~mW}$ ), Raman spectra of Ge nanoparticles exposed to a He-Ne laser light with an excitation wavelength of $633 \mathrm{~nm}$ (laser power $=2 \mathrm{~mW}$ ) from $40 \mathrm{~min}$ to $100 \mathrm{~min}$, schematic of the growth of free-standing Ge nanoparticles upon exposure of a $2 \mathrm{~mW}$ He-Ne laser, schematic representation of energy states referring to crystalline and amorphous state of germanium and two videos (a) and (b) on the explosive crystallisation effect. 